\title{
Malnutrition, Inflammation and Reverse Epidemiology in Hemodialysis Patients
}

\author{
Rodney G. Bowden, Neil A. Schwarz and Brian D. Shelmadine \\ Baylor University, Waco, TX \\ USA
}

\section{Introduction}

Reverse epidemiology, or risk factor paradox, has been used to describe the observed effect that traditional risk factors for cardiovascular disease may not necessarily signify the same risk for hemodialysis patients (HP) as for healthy populations. In fact, recent published findings have suggested counter-intuitive outcomes (Chavalitdhamrong, Danovitch, \& Bunnapradist, 2007; Tsirpanlis et al., 2009) regarding the role cholesterol may play in disease progression in HP with chronic inflammation and malnutrition comorbidities (Dungan, Guster, DeWalt, \& Buse, 2007). However, contemporary experimental studies regarding reverse epidemiology are lacking. The few published findings on this topic suggest chronic inflammation, as measured by C-reactive protein (CRP), and malnutrition, as measured by albumin, is associated with normal cholesterol levels yet higher levels of mortality (Chavalitdhamrong, et al., 2007; Chmielewski, Carrero, Nordfors, Lindholm, \& Stenvinkel, 2008).

In contrast, traditional risk factors such dyslipidemia, hyperhomocysteinemia, obesity, or hypertension may provide protective effects in HP, at least in the short term (KalantarZadeh, Block, Humphreys, \& Kopple, 2003). Important predictors of clinical outcomes in HP are protein-energy wasting (malnutrition) (PEM) and inflammation (Fleischmann, Bower, \& Salahudeen, 2001; Kalantar-Zadeh \& Kopple, 2001; Kopple, 1997; Kopple, Zhu, Lew, \& Lowrie, 1999; Lowrie \& Lew, 1990; Nishizawa, Shoji, Ishimura, Inaba, \& Morii, 2001). Because inflammation and PEM are interconnected and similarly affect markers of nutritional status both are considered part of a malnutrition inflammation complex (MIC) (Kalantar-Zadeh, et al., 2003; Kalantar-Zadeh \& Kopple, 2001; Kalantar-Zadeh, Kopple, Block, \& Humphreys, 2001). Thus, this chapter will address inflammation, malnutrition, cholesterol, and the overall concept of reverse epidemiology in HP relative to MIC as well as the implications of this information on short- and long-term treatment.

\section{Inflammation in hemodialysis patients}

\subsection{Acute vs. chronic inflammation}

Initially, the inflammatory response is a defense mechanism to cellular injury or pathogenic invasion. The acute response includes vasodilatation, hyperemia and vascular permeability and can be detected within a relatively short amount of time (minutes to days) via an increase in neutrophils and the presence of fluid protein exudates (Sprague \& Khalil, 2009). 
Additional responders involved in the inflammatory response are cytokines (Sprague \& Khalil, 2009) and acute phase proteins, which reach peak circulating levels within two days in the acute setting (Ceciliani, Giordano, \& Spagnolo, 2002). Typically, the inflammatory process ceases when the mechanism responsible for cellular injury is removed, subsequent cellular intermediaries are inhibited, and healing takes place (Sprague \& Khalil, 2009). However, in some instances that inflammatory process is not resolved. Thus, the response remains active and proceeds into a chronic process, which can result in necrosis and/or loss of functional tissue.

\subsection{Markers of inflammation in hemodialysis patients}

In HP the inflammatory response and markers of inflammation, namely CRP and the inflammatory cytokine interleukin-6 (IL-6), are predictive of mortality (Barreto et al., 2009; Pecoits-Filho, Barany, Lindholm, Heimburger, \& Stenvinkel, 2002; Stenvinkel, Barany, Heimburger, Pecoits-Filho, \& Lindholm, 2002; Yeun, Levine, Mantadilok, \& Kaysen, 2000; Zimmermann, Herrlinger, Pruy, Metzger, \& Wanner, 1999). In addition to CRP and IL-6, albumin and the inflammatory cytokine tumor necrosis factor-alpha (TNF- $\alpha$ ) are markers of inflammation commonly found in the literature. Each marker can provide evidence regarding the inflammatory state of $\mathrm{HP}$, but there is debate as to which marker should be used and even debate as to the role in the inflammatory process of certain markers, namely CRP. For example, IL-6 and TNF- $\alpha$ are known pro-inflammatory cytokines and are also associated with declining kidney function. Various cells including, macrophages and mast cells, produce TNF- $\alpha$ and IL-6 (Sprague \& Khalil, 2009). Among the numerous effects of TNF- $\alpha$ are the stimulation of a febrile response, up-regulation of other cytokines, such as IL6, and stimulation of acute phase reactants (Sprague \& Khalil, 2009). IL-6, in turn, has pleiotropic effects that include antibody secretion, the acute phase response and has also been shown to be pro-atherogenic, to name a few. However, TNF- $\alpha$ and IL- 6 are not typically used in clinical medicine and are more often found in research; therefore other means of assessing inflammation are used as these tests can become costly. Conversely, albumin and CRP are measurements of inflammation readily available to physicians. Interestingly, albumin levels are also commonly used to assess nutritional status as both nutrition and inflammation can affect albumin (more on this topic will be presented later in the chapter).

$\mathrm{CRP}$, however, is frequently used to confirm the presence of inflammation, as it is an acute phase protein produced by the liver and greatly regulated by IL-6. Additionally CRP is associated with reduction in nitric oxide production, induces monocyte recruitment and plays a strong role in foam cell formation. However, the causal role of CRP in cardiovascular events is still being debated (Genest, 2010; Lippi, Favaloro, Montagnana, \& Franchini, 2010; Sattar \& Lowe, 2006) and the use of CRP must be justified as it incurs added cost (Kaysen, 2009). Regardless, it is a marker of inflammation that in the native form consists of five noncovalently bonded subunits and is termed pentameric CRP or pCRP. This is typically the CRP measured in plasma or serum, and is also known as high sensitivity CRP (hsCRP). High sensitivity CRP can dissociate into monomeric CRP (mCRP) after binding with activated platelets (Eisenhardt et al., 2009). New evidence suggests that mCRP, through the interaction of hsCRP with activated platelets, may play a more dominant role in the inflammatory process than hsCRP as mCRP was found to colocalize with macrophages and platelets (Eisenhardt, Habersberger, Murphy, et al., 2009). High sensitivity CRP has also 
been found in atherosclerotic lesions (Sun et al., 2005), but the antibodies used to detect CRP in this study detected both pCRP and mCRP (Eisenhardt, Habersberger, \& Peter, 2009). It has been reported that once $\mathrm{pCRP}$ dissociates into $\mathrm{mCRP}, \mathrm{mCRP}$ stimulates monocytes to a greater extent than pCRP, leads to increased monocyte adhesion, and exerts proinflammatory properties (Eisenhardt, Habersberger, Murphy, et al., 2009). Additionally, mCRP may be more effective at regulating LDL metabolism than pCRP (Ji, Wu, Potempa, Qiu, \& Zhao, 2006).

\subsection{Causes of inflammation in hemodialysis patients}

Aside from the primary reason for the patient being placed on hemodialysis, often a disease associated with inflammation, dialysis and the integral pieces of hemodialysis can be sources of inflammation. Kaysen (2009) indicates that the type of vascular access used in dialysis, the insertion of the catheters, biofilm on catheters, bacterial components present in dialysate, and water supply can all be sources of inflammation (Kaysen, 2009). Markers of inflammation associated with vascular access alone include albumin (Chand, Teo, Fatica, \& Brier, 2008; Wystrychowski et al., 2009), CRP (Costa et al., 2008; Movilli et al., 2006; Sachdeva, Kovalchuk, Bitzer, \& Mokrzycki, 2009), and IL-6 (Costa, et al., 2008; Sachdeva, et al., 2009). As Kaysen (2009) points out, the type of vascular access in HP is associated with mortality (Xue, Dahl, Ebben, \& Collins, 2003). Acutely, initial insertion of vascular access, especially catheter or arteriovenous graft (AVG), resulted in transient elevations of CRP and IL-6 whereas arteriovenous fistulas (AVF) did not demonstrate a transient rise in inflammatory markers (Sachdeva, et al., 2009). In regards to chronic inflammation, changing vascular access type from a catheter to AVG was shown to cause an increase in albumin, where as a change from AVG to catheter caused a decrease in albumin (Wystrychowski, et al., 2009). Similarly, catheter and AVG use have been demonstrated to result in elevated levels of CRP and IL-6 and lower levels of albumin than AVF (Costa, et al., 2008; Movilli, et al., 2006). Thus, the type of vascular access has an impact on inflammation levels. An additional impact on inflammation levels is adipose tissue as adipocytes produce IL-6 (Fasshauer, Klein, Lossner, \& Paschke, 2003), which is also a strong predictor of mortality in HP (Barreto, et al., 2009; Pecoits-Filho, et al., 2002; Stenvinkel, et al., 2002).

\section{Malnutrition in hemodialysis patients}

\subsection{Albumin as a marker of nutritional status}

Albumin is the most abundant plasma protein with a half-life of about twenty-one days. It is a negative acute-phase protein that functions to maintain oncotic pressure and act as a transport protein (Carlson, 2004). Normal serum albumin concentration is between 3.5 and $5.2 \mathrm{~g} / \mathrm{dL}$, and this reference range is often utilized as a marker of nutritional status in healthy older populations (Carlson, 2004; Covinsky, Covinsky, Palmer, \& Sehgal, 2002). The cutoff point for low serum albumin concentration (hypoalbuminemia) has been proposed to be even higher at about $3.9 \mathrm{~g} / \mathrm{dL}$ in HP (Trivedi, Xiang, \& Klein, 2009). However, it must be noted that conclusions derived from measures of serum albumin concentration are not always in agreement with the conclusions derived from clinical assessments regarding nutritional status (Covinsky, et al., 2002). Forty HP with CRP levels below $0.80 \mathrm{mg} / \mathrm{dL}$ were evaluated for malnutrition by measuring serum albumin and through the use of the Subjective Global Assessment (SGA) described by Detsky, McLaughlin, and Baker et al. (1987). The SGA was used to determine whether a patient was classified as well-nourished 
or malnourished. Using $3.5 \mathrm{~g} / \mathrm{dL}$ as the cutoff point for hypoalbuminemia resulted in a sensitivity of just $14.3 \%$ compared to the results of the SGA. Raising the hypoalbuminemia cutoff point to $4.1 \mathrm{~g} / \mathrm{dL}$ increased the sensitivity of the measurement to $64 \%$. Furthermore, the mean albumin concentrations for the well-nourished and malnourished groups were 4.3 $\mathrm{g} / \mathrm{dL}$ and $4.0 \mathrm{~g} / \mathrm{dL}$, respectively, with considerable overlap between the two groups. These data suggest that serum albumin alone may not be a sensitive marker of malnutrition in the absence of inflammation in HP (Santos et al., 2003). Regardless, serum albumin is a very important marker of mortality risk in HP (Iseki, Kawazoe, \& Fukiyama, 1993). Despite the lack of total agreement with clinical assessments of nutritional status, hypoalbuminemia has been demonstrated to be an independent risk factor for all-cause mortality in older persons especially when combined with measures of physical disability (Corti, Guralnik, Salive, \& Sorkin, 1994). Additionally, hypoalbuminemia is associated with mortality in various disease populations including cardiovascular, cancer, and HP (Iseki, et al., 1993; Phillips, Shaper, \& Whincup, 1989). A $1 \mathrm{~g} / \mathrm{dL}$ reduction in serum albumin has been associated with a $47 \%$ greater risk of mortality in $\mathrm{HP}$, with the serum albumin concentration in these particular HP being linked to inflammation more so than the presence of malnutrition (de Mutsert et al., 2009).

\subsection{Regulation of serum albumin: malnutrition and inflammation}

Serum albumin concentration is controlled by the rate of its synthesis, fractional catabolic rate (FCR), and distribution between intra and extravascular compartments. These three variables controlling albumin concentration are heavily influenced by both nutritional status and inflammation (Kaysen, 2003). In healthy individuals and HP without inflammation that are malnourished, albumin levels usually stay within a normal range until the degree of starvation is preterminal (Kaysen, 2009). Renal disease is associated with anorexia and PEM due to the build-up of uremic toxins. Additionally, hemodialysis for the removal of these toxins is also associated with anorexia and PEM because of the resulting nausea and postdialysis fatigue (Bergstrom, 1996). PEM leads to a decreased rate of albumin synthesis. In normal individuals, the FCR of albumin and resting energy expenditure are also downregulated in order to compensate for its decreased synthesis during periods of PEM. For HP that are in an inflammatory state, normal down-regulation of FCR is blunted leading to an imbalance between albumin synthesis and catabolism that result in hypoalbuminemia (Kaysen, 2009). Even in the absence of malnutrition, positive acute phase proteins that result from the production of pro-inflammatory cytokines are associated with decreased albumin synthesis. Additionally, inflammation leads to a greater than normal albumin FCR for a given serum albumin level (Kaysen, 2003). On top of the challenges presented by malnutrition and inflammation in HP, amino acid loss from hemodialysis itself may contribute further to nitrogen restriction and hypoalbuminemia (Kaysen, 2009).

\subsection{Nutritional supplementation and hemodialysis patients}

Recently, studies have investigated the effects of protein and amino acid supplements on serum albumin levels in HP (Bolasco, Caria, Cupisti, Secci, \& Saverio Dioguardi, 2011; Moretti, Johnson, \& Keeling-Hathaway, 2009; Taylor et al., 2011). When selecting an appropriate nutritional supplement for HP, phosphorus levels must be taken into consideration as it has been demonstrated that high-protein intake with concurrent lowphosphorus ingestion and normal serum phosphorus levels is associated with the lowest 
mortality rate among HP (Kalantar-Zadeh et al., 2010). Supplementation with 15 grams of liquid hydrolyzed collagen protein three times per week after each hemodialysis treatment in one crossover group increased serum albumin by month 3 of supplementation. However, this change was small $(+0.03 \mathrm{~g} / \mathrm{dL})$ and was not sustained throughout the remaining 3 months of treatment (Moretti, et al., 2009). Conversely, two pilot studies have shown promising effects of nutritional supplementation on serum albumin. In one study, maintenance HP consumed eight ounces of egg whites (egg whites are low in phosphorus) once per day for six weeks (Taylor, et al., 2011). Mean serum albumin concentrations increased by $0.19 \mathrm{~g} / \mathrm{dL}$ along with a fall in mean serum phosphorus of $0.94 \mathrm{mg} / \mathrm{dL}$. In the other pilot study, four grams of oral amino acid supplementation three times daily increased mean serum albumin concentration by $0.50 \mathrm{~g} / \mathrm{dL}$ after 3 months of treatment (Covinsky, et al., 2002). Also, inflammation was attenuated in the study group as demonstrated by a decrease in CRP levels. Based on these pilot studies, protein and amino acid supplementation may benefit $\mathrm{HP}$, but more research including larger sample sizes with controlled trials is needed before a definite conclusion or treatment protocol can be formulated.

\section{Cardiovascular disease and hemodialysis patients}

The number of HP patients in the United States is approximately 350,000 with an expectation of reaching 1.5 million by 2016. Most HP have a significant decline in quality of life with two-thirds dying within 5 years of dialysis initiation; a survival rate worse than most cancers (Kilpatrick et al., 2007). Cardiovascular disease (CVD) is a leading cause of death in HP with rates higher than the general population and risk primarily associated with elevated lipids, inflammation, malnutrition, hypertension, hyperhomocysteinemia, obesity, and insulin resistance (Third Report of the National Cholesterol Education Program Expert Panel on Detection, Evaluation, and Treatment of High Blood Cholesterol in Adults (Adult Treatment Panel III) Final Report, 2002). Most HP patients' elevated lipid profiles are associated with a higher incidence of CVD morbidity and mortality (Vaziri, 2009) and allcause mortality (Tsirpanlis, et al., 2009). Additionally, non-fatal CVD is 10-30 times higher in $\mathrm{HP}$ suggesting this population is more prone to heart disease (Nanayakkara \& Gaillard, 2010). Though traditional treatment of CVD in HP has demonstrated promise, many large randomized trials in HP have not demonstrated a survival benefit from traditional treatment strategies (Nanayakkara \& Gaillard, 2010). The challenge becomes understanding why traditional risk factors are less predictive and whether the progression of disease is so advanced in HP that risk factor management should be different in this patient population. It should be noted however, that traditional and non-traditional risk factors for CVD in HP do have some crossover, complicating our understanding of how risk factor management may assist in disease causation and association. Though this chapter focuses on HP, chronic kidney disease patients who are predialysis share some of the same counter-intuitive findings. Therefore it should be noted that progression of CVD begins well before HP begin dialysis and could be detected as early as stage I CKD. Finally, it has been suggested that plaque accumulation may occur differently in HP. In the general population arterial plaque is more associated with lipid accumulation, but with HP it is more likely to be associated with calcified plaques and increased arterial stenosis (Diepeveen, Wetzels, Bilo, van Tits, \& Stalenhoef, 2008). Various research groups, including the National Cholesterol Education Program (NCEP) (Third Report of the National Cholesterol Education Program Expert Panel on Detection, 
Evaluation, and Treatment of High Blood Cholesterol in Adults (Adult Treatment Panel III) Final Report, 2002) have established that lipids play a significant role in the progression of CVD and with reductions in cholesterol levels there is a similar and graded reduction in risk (Kalantar-Zadeh, et al., 2003). Dyslipidemia characterized in HP is primarily associated with hypertriglyceridemia, low HDL concentrations, elevated levels of LDL, elevated LDL particle numbers, a higher propensity of smaller and denser LDL particles which contain high levels of residual triglycerides, and elevated levels of lipoprotein (a) (Vaziri, 2009).

Cholesterol metabolism in HP can be significantly altered by dialysis protocol, lipid controlling medication, malnutrition, and inflammation (Montazerifar, Hashemi, Karajibani, \& Dikshit, 2010). HDL can be significantly reduced in HP due to a reduced plasma concentration of ApoA-I and ApoA-II (Bowden, Hebert, Wilson, Gentile, \& Lanning, 2007; Vaziri, 2009), reduced transporter proteins such as ABCA-1 (Vaziri, 2009), and the downregulation of enzymatic process associated with HDL maturation (Malgorzewicz et al., 2010). Down-regulation also occurs with HDL paraoxonase which is associated with impaired protection against oxidative stress. Hypertriglyceridemia also occurs in HP, is normally associated with impaired VLDL and is the most prominent dyslipidemic abmormality reported in 70\% of HP (Eisenhardt, Habersberger, \& Peter, 2009). Additionally, hypertriglyceridemia is associated with increases in IDL, chylomicrons, and chylomicron remnants postprandial (Chmielewski, et al., 2008). Primarily a reduction in lipoprotein lipase, an enzyme associated with binding to VLDL and the release of the corresponding triglycerides, is associated with changes that cause a concomitant increase in plasma triglycerides that seems to correspond with a decrease in VLDL receptors. Finally, LDL in $\mathrm{HP}$ is normally more atherogenic as particles are usually smaller, denser and are more likely to be oxidized and engulfed by macrophages leading to more unstable arterial plaques (Kaysen, 2009). Oxidation can further cause LDL to no longer be recognizable to LDL receptors on the cell causing less deposition of LDL in intracellular pools. Less deposition can lead to the same amount of circulating LDL cholesterol being associated with smaller and denser LDL particles which can carry more risk for CVD. Excess LDL cholesterol is then removed from circulation primarily by being engulfed by macrophages which lead to more atherogenic foam cells leading to risk acceleration. Lipoprotein (a) is a LDL-like lipid with higher levels associated with increased risk of CVD and is associated with overproduction of apolipoproteins, specifically apoB. Apolipoprotein B is bound with LDL and is associated with increased numbers of LDL particles.

\subsection{Reverse epidemiology}

Though cholesterol metabolism in HP is associated with dyslipidemia and many CVD related deaths are associated with elevated levels of lipoproteins, recent evidence suggests that many HP have normal or reduced plasma cholesterol levels that are associated with a higher rate of mortality (Bowden \& Wilson, 2010). CVD related mortality accounts for 40$45 \%$ of all-cause mortality in HP suggesting factors other than lipids may be associated with CVD in this patient population (Dungan, et al., 2007; Tsirpanlis, et al., 2009). Counterintuitive outcomes regarding the role cholesterol may play in disease progression in HP may be affected by chronic inflammation and malnutrition with much of the published literature concerned with MIC (Bowden \& Wilson, 2010; Chavalitdhamrong, et al., 2007). The term, though controversial, that has been used in the literature associated with this counter-intuitive finding is reverse epidemiology (Dungan, et al., 2007). Experimental 
studies are deficient, but the few published on this topic have suggested that HP with chronically elevated levels of inflammation, as measured by C-reactive protein (CRP) or interleukin-6 (IL-6), and malnutrition, as measured by albumin, are associated with normal cholesterol values but higher levels of mortality (Chavalitdhamrong, et al., 2007; Chmielewski, et al., 2008).

\section{Malnutrition-inflammation complex}

Cano et al. (2009) has reported that between $20-60 \%$ of HP may have MIC and that patients also have lower body weights, lower BMI, lower albumin levels, lower blood pressure and elevated CRP (Diepeveen, et al., 2008). Albumin has been specifically mentioned as a marker of nutritional status and identified as one of the criteria used to measure PEM which is associated with MIC. The association between hypoalbuminemia $(<3.9 \mathrm{mg} / \mathrm{dL})$ and mortality has been well-established and albumin has been identified as a strong predictor of cardiovascular disease (Kaysen, 2009). Supporting this theory is the fact that most studies reporting on reverse epidemiology report no counter-intuitive findings with HDL. The cholesterol esters in HDL are primarily received from albumin (Vaziri, 2009) and therefore hypoalbuminemia would be associated with low HDL. This is also one possible explanation for why other lipoproteins would be low, yet still associated with a significantly higher mortality rate in HP. Challenging our understanding of how this might impact mortality and cholesterol is that albumin is also used as a measure of inflammation and may not necessarily be related a nutritional etiology (Trivedi, et al., 2009). Finally, CRP along with IL6 are inflammatory markers that have been associated with higher rates of mortality as well (Bowden \& Wilson, 2010).

\subsection{Reverse epidemiology and cholesterol}

In a subset of HP a decrease in baseline cholesterol levels, excluding HDL, has been associated with decreases in CVD mortality and all-cause mortality when patients have chronic levels of inflammation and poor nutritional status (Krane et al., 2009). Recent study authors have suggested the need to consider both malnutrition and inflammation simultaneously as albumin has been shown to be affected by inflammation levels. Inflammatory cytokines and acute phase reactants have been reported to decrease appetite, reduced albumin, increase catabolism (Liu et al., 2004) and quite possibly cause lower levels of cholesterol suggesting that low albumin levels may simply be a reflection of inflammation rather than malnutrition. Specifically most lipoproteins seem to be affected by MIC with the exception of HDL. In most studies where HDL was either low or unaffected most patients experience hypoalbuminemia and low protein intake in the diet (Kilpatrick, et al., 2007). Krane et al. (2009) in a study of 1,229 Type II diabetics who were HP reported that high levels of CRP strongly predicted all-cause mortality, sudden death and myocardial infarction when cholesterol levels were both low and high. Yet, when CRP levels were high and cholesterol levels were low, relative risks for CVD related deaths were even greater. It was further reported that CRP level and not LDL level was the variable more likely to predict risk for mortality and cardiovascular events. Another study confirmed the existence of reverse epidemiology in the presence of high inflammation suggesting the inflammation better predicted both morbidity and mortality (Tsirpanlis, et al., 2009). The study authors also reported that nutritional cachexia along with low cholesterol were good nutritional indices for malnutrition and may be the reason low cholesterol levels are associated with 
higher levels of mortality in HP. A more recent study reported on the cross-sectional association with MIC and the effects on cholesterol in HP (Bowden \& Wilson, 2010). When comparing cholesterol levels, those classified as having hypoalbuminemia had a reverse epidemiological effect with LDL particle number. In the same study when HP were classified as having high inflammation, based on CRP, LDL, VLDL, and LDL particle number reported counter-intuitive findings. But, in patients classified as having both hypoalbuminemia and high inflammation, all lipid variables, with the exception of HDL, reported a reverse epidemiological effect. This suggests that though inflammation may play a more prominent role with reverse epidemiology, both inflammation and malnutrition can have a pronounced effect on lipids causing low cholesterol levels to be associated with more mortality. Additionally, other study authors have reported inverse associations with cholesterol and all-cause mortality, but also a U-shaped relationship with cholesterol in the presence of malnutrition and inflammation (Liu, et al., 2004). When malnutrition and inflammation were controlled for in the analysis, a strong, graded and positive association existed between high cholesterol levels and mortality further supporting the thought that reverse epidemiological associations with cholesterol in HP is associated with MIC. An additional review paper has suggested that previous studies that have controlled statistically for factors associated with MIC in HP, risk associated with cholesterol was the same as the general population and further speculates that cholesterol may be an additional marker of malnutrition (Chmielewski, et al., 2008). It should be noted that not all studies agree with these findings.

Another theory behind why low cholesterol in HP patients can be associated with high mortality has been called survival selection. It is well-established that most chronic kidney disease patients will not survive to kidney failure and End-Stage Renal Disease. Presently, it is suggested that only $10 \%$ (Trivedi, et al., 2009) of patients will live long enough to initiate dialysis. Therefore, since so few survive it is thought that only those who have a strong genetic predisposition for survival may be more likely to live but may also have a poorer risk profile. Additionally, simply stated, HP may not live long enough to die of the consequences of traditional CVD risk factors. Though this theory is not very new, it has yet to be confirmed with well controlled studies that take into consideration the age of the patients. Kalantar-Zadeh et al. (2003) also suggests that reverse epidemiology may be normal and that over-nutrition is primarily a $20^{\text {th }}$ and $21^{\text {st }}$ century phenomenon and that our understanding of traditional Framingham risk factors may in fact be new and the exception. Though over-nutrition is a problem in many countries it has been associated with longer living populations in Western nations. As one would expect this idea is highly controversial among scientist and nephrologists.

Additional study authors (Nanayakkara \& Gaillard, 2010) have reported reverse epidemiology in HP concerning lipids could possibly be due oxidative stress. Reactive oxygen species (ROS) production that is not balanced by antioxidant control is associated with oxidative stress. Furthermore, oxidative injury has been reported to alter lipids in both the general population and HP and is involved in CVD acceleration (Diepeveen, et al., 2008). Though HP are normally supplemented with B vitamins and folic acid, many still have deficiencies in antioxidants with many patients shifting to a more pro-oxidative stress profile. High oxidized LDL is a well established comorbidity in both HP and CKD patients and is associated with small, dense LDL particles. Moreover, modification of LDL through oxidation is thought to be the first step in the development of CVD and specifically atherosclerosis. Oxidative stress occurs routinely in HP, especially in patients with a long- 
term dialysis vintage, making LDL smaller and denser and is associated with more endothelial dysfunction, inflammation, stenosis and intima media thickness. Therefore, the oxidative stress hypothesis may help to further explain reverse epidemiology. Oxidative stress in combination with MIC could cause lower levels of LDL and LDL particle numbers, but more atherogenic particles that can accelerate mortality and morbidity. Yet, those associations do exist, a causal relationship between oxidative stress, CVD, and reverse epidemiology has yet to be established suggesting the need for further study.

Chmielewski (2008) reports on an endotoxinlipoprotein hypothesis that suggests higher levels of cholesterol may be beneficial in HP. The theory suggests that higher levels of lipoproteins more readily bind bacterial lipopolysaccharide or endotoxins and modulate inflammatory immune responses. The authors continues to state that cholesterol levels and their ability to predict CVD fall on a continuum with lower and higher levels associated with mortality (Kalantar-Zadeh, 2007). Liu, et al. (2004) may help support this theory as they have reported a U-shaped curve regarding cholesterol levels and moratlity in HP. This theory is highly speculative and needs further study.

Finally, as mentioned previously, HP patients have been reported to have smaller, dense LDL particles that are more oxidized which may play a stronger role than LDL. Small LDL particle size has been identified as an emerging risk factor for CVD (Third Report of the National Cholesterol Education Program Expert Panel on Detection, Evaluation, and Treatment of High Blood Cholesterol in Adults (Adult Treatment Panel III) Final Report, 2002). A previous study (Bowden, Griggs, Wilson, \& Gentile, 2009) has demonstrated that LDL particle number and LDL size can classify more HP at risk when compared to LDL and triglycerides. Since more HP have small, dense LDL particles there may be mortality associated with smaller LDL particles even when LDL particle number is lower. Therefore, though HP may have less LDL cholesterol and less of the smaller LDL particles, because smaller LDL particles are more atherogenic, more patients have increased morality with decrease levels of cholesterol.

\section{Treatment}

Reverse epidemiology has been associated with cholesterol but also body mass index (BMI), systolic and diastolic blood pressure, homocysteine, and creatinine levels (Balakrishnan \& Rao, 2007) in HP suggesting the need for novel treatments. Since the counter-intuitive findings are prevalent in HP additional approaches are necessary to help identify novel treatments and to discover if new therapies are warranted. Though counter-intuitive findings are present in HP as well as advanced age, congestive heart failure, malignancies, and AIDS little data exists to support changes in non-traditional risk factors as a means to control CVD. To help increase albumin levels it has been proposed to increase protein content in the diet. But levels of protein augmentation with HP patients on chronic hemodialysis has not been sufficiently elucidated simply because dietary protein can be a significant source of uremic toxins and increase phosphate levels which can have deleterious effects on the health of HP patients (Stolic, 2010). It should be noted that hypercaloric consumption may take several years and even decades for serious health effects to occur, yet hypocaloric consumption, measured by albumin levels in HP patients, normally causes a more rapid deterioration in health. Combined with high inflammation levels, a decreased appetite and hypocaloric levels may cause a significant decrease in cholesterol but accelerated risk for mortality (Kalantar-Zadeh, et al., 2001). This short-term effect of 
malnutrition enhanced by inflammation may overcome the long-term impact of traditional risk factors for CVD and may cause the HP patients to not live long enough to develop elevated levels of cholesterol causing them die sooner than is expected. Also, evidence suggests that lipid levels become more elevated and more strongly associated with CVD the longer the HP receives dialysis and suggests that even though counter-intuitive cholesterol findings are evident in early dialysis traditional therapies such as statins, fibrates and niacin are necessary even with cholesterol levels are low (Chavalitdhamrong, et al., 2007). Therefore, treatment for HP patients with MIC needs to focus short-term on inflammation and malnutrition through dietary counseling and medication. Once MIC is controlled, a more long-term therapy may need to look at controlling lipids associated with CVD risk.

\section{Conclusions}

Reverse epidemiology in cholesterol levels associated with HP introduces a number of questions concerning our understanding of CVD and findings from the Framingham study. The questions becomes whether nephrologists should recommend the same cut-points for HP as is normally used in general populations. Should nephrologists attempt to control malnutrition and inflammation first and focus on lipids once HP have MIC under control? Though statins can help control lipids they may also help control inflammation which in turn may help to regulate appetite and increase albumin levels suggestions that statin therapy may still need to be used in most HP. Finally, more clinical trials are needed to discover if reverse epidemiology is "normal" in HP or simply a new understanding of traditional risk factors.

\begin{tabular}{|c|c|c|c|c|c|}
\hline Author & Year & Sample & Population & $\begin{array}{c}\text { Study } \\
\text { Design }\end{array}$ & Study Findings \\
\hline $\begin{array}{l}\text { Bowden, } \\
\text { et al }\end{array}$ & $\begin{array}{l}\text { In } \\
\text { Press }\end{array}$ & 438 & $\mathrm{HP}$ & $\begin{array}{l}\text { Prospective } \\
\sim 3 \text { years }\end{array}$ & $\begin{array}{l}\text { Reverse epidemiological } \\
\text { effects for total cholesterol, } \\
\text { LDL, LDL particle number, } \\
\text { LDL, triglycerides, and } \\
\text { VLDL }\end{array}$ \\
\hline $\begin{array}{l}\text { Bowden, } \\
\text { et al }\end{array}$ & 2010 & 105 & $\mathrm{HP}$ & $\begin{array}{l}\text { Cross- } \\
\text { sectional }\end{array}$ & $\begin{array}{l}\text { Reverse epidemiology in } \\
\text { number in } \\
\text { hypoalbuminemia group; } \\
\text { LDL, VLDL, and LDL } \\
\text { particle number in inflamed } \\
\text { group; total cholesterol, } \\
\text { VLDL, large VLDL, } \\
\text { triglycerides, Lp(a), LDL, } \\
\text { and LDL particle number in } \\
\text { hypoalbuminemia and } \\
\text { inflamed group }\end{array}$ \\
\hline $\begin{array}{l}\text { Bowden, } \\
\text { et al }\end{array}$ & 2009 & 117 & $\mathrm{HP}$ & $\begin{array}{l}\text { Cross- } \\
\text { sectional }\end{array}$ & $\begin{array}{l}\text { Reverse epidemiology effect } \\
\text { existed for LDL, large LDL, } \\
\text { LDL particle size, and HDL }\end{array}$ \\
\hline $\begin{array}{l}\text { Krane, } \\
\text { et al }\end{array}$ & 2009 & 1255 & $\begin{array}{l}\text { HP with } \\
\text { Type II } \\
\text { Diabetes }\end{array}$ & $\begin{array}{l}\text { Prospective } \\
\sim 4 \text { years }\end{array}$ & $\begin{array}{l}\text { Patients with low } \\
\text { cholesterol and high } \\
\text { inflammation had an }\end{array}$ \\
\hline
\end{tabular}




\begin{tabular}{|c|c|c|c|c|c|}
\hline & & & & & $\begin{array}{l}\text { adjusted relative risk } \\
\text { equivalent to patients with } \\
\text { high cholesterol and low } \\
\text { inflammation in CVD death } \\
\text { and all-cause mortality }\end{array}$ \\
\hline $\begin{array}{l}\text { Tsirpanlis, } \\
\text { et al }\end{array}$ & 2009 & 136 & $\mathrm{HP}$ & $\begin{array}{l}\text { Prospective } \\
\sim 2 \text { years }\end{array}$ & $\begin{array}{l}\text { Low cholesterol levels } \\
\text { together with selected } \\
\text { inflammatory markers } \\
\text { predict CVD and all-cause } \\
\text { mortality and morbidity }\end{array}$ \\
\hline $\begin{array}{l}\text { Kilpatrick, } \\
\text { et al }\end{array}$ & 2007 & 15,859 & $\mathrm{HP}$ & $\begin{array}{l}\text { Prospective } \\
\sim 3 \text { years }\end{array}$ & $\begin{array}{l}\text { Inverse associations } \\
\text { between hyperlipidemia } \\
\text { and survival, however, } \\
\text { black HP with high LDL } \\
\text { show almost two-fold } \\
\text { increase in cardiovascular } \\
\text { death risk }\end{array}$ \\
\hline Liu, et al & 2004 & 823 & $\mathrm{HP}$ & $\begin{array}{l}\text { Prospective } \\
\sim 3 \text { years }\end{array}$ & $\begin{array}{l}\text { Inverse association of } \\
\text { cholesterol levels with all- } \\
\text { cause mortality and a U- } \\
\text { shaped relationship with } \\
\text { CVD mortality in the } \\
\text { presence of } \\
\text { inflammation/malnutrition }\end{array}$ \\
\hline Iseki, et al & 2002 & 1167 & $\mathrm{HP}$ & $\begin{array}{l}\text { Prospective } \\
\sim 10 \text { years }\end{array}$ & $\begin{array}{l}\text { Hypercholesterolemia was } \\
\text { an independent predictor } \\
\text { on survival but was only } \\
\text { evident in a sub-group of } \\
\text { patients whose serum } \\
\text { albumin was more than } 4.5 \\
\mathrm{~g} / \mathrm{dl}\end{array}$ \\
\hline
\end{tabular}

Table 1. Studies reporting a reverse epidemiology affect regarding cholesterol and HP (2002Present).

\section{References}

Balakrishnan, V. S., \& Rao, M. (2007). Genetics and reverse epidemiology among patients on chronic hemodialysis. Seminars in Dialysis, 20(6), 570-576.

Barreto, D. V., Barreto, F. C., Liabeuf, S., Temmar, M., Lemke, H. D., Tribouilloy, C., et al. (2009). Plasma interleukin-6 is independently associated with mortality in both hemodialysis and pre-dialysis patients with chronic kidney disease. Kidney International, 77(6), 550-556.

Bergstrom, J. (1996). Anorexia in dialysis patients. Seminars in Nephrology, 16(3), 222-229.

Bolasco, P., Caria, S., Cupisti, A., Secci, R., \& Saverio Dioguardi, F. (2011). A novel amino acids oral supplementation in hemodialysis patients: a pilot study. Renal Failure, 33(1), 1-5. 
Bowden, R. G., Griggs, J., Wilson, R. L., \& Gentile, M. (2009). Cholesterol values are poor markers of disease risk in a chronic disease population. Clinical Lipidology, 4(5), 545551.

Bowden, R. G., Hebert, S., Wilson, R., Gentile, M., \& Lanning, B. A. (2007). Comparison of lipid measures and risk stratification among end-stage renal disease patients. $J$ Nephrol, 20(2), 212-218.

Bowden, R. G., \& Wilson, R. L. (2010). Malnutrition, inflammation, and lipids in a cohort of dialysis patients. Postgraduate Medicine, 122(3), 196-202.

Cano, N. J., Miolane-Debouit, M., Leger, J., \& Heng, A. E. (2009). Assessment of body protein: energy status in chronic kidney disease. Seminars in nephrology, 29(1), 59-66.

Carlson, T. H. (2004). Laboratory Data in Nutrition Assessment. In L. K. Mahan \& S. EscottStump (Eds.), Krause's Food, Nutrition, E Diet Therapy (11th ed., pp. 436-454). Philadelphia, PA: Saunders.

Ceciliani, F., Giordano, A., \& Spagnolo, V. (2002). The systemic reaction during inflammation: the acute-phase proteins. Protein and Peptide Letters, 9(3), 211-223.

Chand, D. H., Teo, B. W., Fatica, R. A., \& Brier, M. (2008). Influence of vascular access type on outcome measures in patients on maintenance hemodialysis. Nephron Clinical Practice 108(2), c91-98.

Chavalitdhamrong, D., Danovitch, G. M., \& Bunnapradist, S. (2007). Is there a reversal of reverse epidemiology in renal transplant recipients? Seminars in Dialysis, 20(6), 544548.

Chmielewski, M., Carrero, J. J., Nordfors, L., Lindholm, B., \& Stenvinkel, P. (2008). Lipid disorders in chronic kidney disease: reverse epidemiology and therapeutic approach. Journal of Nephrology, 21(5), 635-644.

Corti, M. C., Guralnik, J. M., Salive, M. E., \& Sorkin, J. D. (1994). Serum albumin level and physical disability as predictors of mortality in older persons. The Journal of the American Medical Association, 272(13), 1036-1042.

Costa, E., Rocha, S., Rocha-Pereira, P., Castro, E., Reis, F., Teixeira, F., et al. (2008). Cross-talk between inflammation,coagulation/fibrinolysis and vascular access in hemodialysis patients. The Journal of Vascular Access, 9(4), 248-253.

Covinsky, K. E., Covinsky, M. H., Palmer, R. M., \& Sehgal, A. R. (2002). Serum albumin concentration and clinical assessments of nutritional status in hospitalized older people: different sides of different coins? Journal of the American Geriatrics Society, 50(4), 631-637.

de Mutsert, R., Grootendorst, D. C., Indemans, F., Boeschoten, E. W., Krediet, R. T., \& Dekker, F. W. (2009). Association between serum albumin and mortality in dialysis patients is partly explained by inflammation, and not by malnutrition. Journal of Renal Nutrition 19(2), 127-135.

Detsky, A. S., McLaughlin, J. R., Baker, J. P., Johnston, N., Whittaker, S., Mendelson, R. A., et al. (1987). What is subjective global assessment of nutritional status? Journal of Parenteral and Enteral nutrition, 11(1), 8-13.

Diepeveen, S. H., Wetzels, J. F., Bilo, H. J., van Tits, L. J., \& Stalenhoef, A. F. (2008). Cholesterol in end-stage renal disease: the good, the bad or the ugly? [Review]. The Netherlands journal of medicine, 66(2), 53-61. 
Dungan, K. M., Guster, T., DeWalt, D. A., \& Buse, J. B. (2007). A comparison of lipid and lipoprotein measurements in the fasting and nonfasting states in patients with type 2 diabetes. Current Medical Research and Opinion, 23(11), 2689-2695.

Eisenhardt, S. U., Habersberger, J., Murphy, A., Chen, Y. C., Woollard, K. J., Bassler, N., et al. (2009). Dissociation of pentameric to monomeric C-reactive protein on activated platelets localizes inflammation to atherosclerotic plaques. Circulation Research, 105(2), 128-137.

Eisenhardt, S. U., Habersberger, J., \& Peter, K. (2009). Monomeric C-reactive protein generation on activated platelets: the missing link between inflammation and atherothrombotic risk. Trends in Cardiovascular Medicine 19(7), 232-237.

Fasshauer, M., Klein, J., Lossner, U., \& Paschke, R. (2003). Interleukin (IL)-6 mRNA expression is stimulated by insulin, isoproterenol, tumour necrosis factor alpha, growth hormone, and IL-6 in 3T3-L1 adipocytes. Hormone and Metabolic Research, 35(3), 147-152.

Fleischmann, E. H., Bower, J. D., \& Salahudeen, A. K. (2001). Risk factor paradox in hemodialysis: better nutrition as a partial explanation. Asaio Journal, 47(1), 74-81.

Genest, J. (2010). C-reactive protein: risk factor, biomarker and/or therapeutic target? The Canadian Journal of Cardiology, 26 Suppl A, 41A-44A.

Iseki, K., Kawazoe, N., \& Fukiyama, K. (1993). Serum albumin is a strong predictor of death in chronic dialysis patients. Kidney International, 44, 115-119.

Ji, S. R., Wu, Y., Potempa, L. A., Qiu, Q., \& Zhao, J. (2006). Interactions of C-reactive protein with low-density lipoproteins: implications for an active role of modified C-reactive protein in atherosclerosis. The International Journal of Biochemistry \& Cell Biology, 38(4), 648-661.

Kalantar-Zadeh, K. (2007). What is so bad about reverse epidemiology anyway? Seminars in Dialysis, 20(6), 593-601.

Kalantar-Zadeh, K., Block, G., Humphreys, M. H., \& Kopple, J. D. (2003). Reverse epidemiology of cardiovascular risk factors in maintenance dialysis patients. Kidney International, 63(3), 793-808.

Kalantar-Zadeh, K., Gutekunst, L., Mehrotra, R., Kovesdy, C. P., Bross, R., Shinaberger, C. S., et al. (2010). Understanding sources of dietary phosphorus in the treatment of patients with chronic kidney disease. Clinical journal of the American Society of Nephrology : CJASN, 5(3), 519-530.

Kalantar-Zadeh, K., \& Kopple, J. D. (2001). Relative contributions of nutrition and inflammation to clinical outcome in dialysis patients. American Journal of Kidney Diseases, 38(6), 1343-1350.

Kalantar-Zadeh, K., Kopple, J. D., Block, G., \& Humphreys, M. H. (2001). A malnutritioninflammation score is correlated with morbidity and mortality in maintenance hemodialysis patients. American Journal of Kidney Diseases, 38(6), 1251-1263.

Kaysen, G. A. (2003). Serum albumin concentration in dialysis patients: why does it remain resistant to therapy? Kidney international. Supplement(87), S92-98.

Kaysen, G. A. (2009). Biochemistry and biomarkers of inflamed patients: why look, what to assess. Clinical Journal of the American Society of Nephrology : CJASN, 4 Suppl 1, S5663.

Kilpatrick, R. D., McAllister, C. J., Kovesdy, C. P., Derose, S. F., Kopple, J. D., \& KalantarZadeh, K. (2007). Association between serum lipids and survival in hemodialysis 
patients and impact of race. Journal of the American Society of Nephrology 18(1), 293303.

Kopple, J. D. (1997). Nutritional status as a predictor of morbidity and mortality in maintenance dialysis patients. Asaio Journal, 43(3), 246-250.

Kopple, J. D., Zhu, X., Lew, N. L., \& Lowrie, E. G. (1999). Body weight-for-height relationships predict mortality in maintenance hemodialysis patients. Kidney Int, 56(3), 1136-1148.

Krane, V., Winkler, K., Drechsler, C., Lilienthal, J., Marz, W., \& Wanner, C. (2009). Association of LDL cholesterol and inflammation with cardiovascular events and mortality in hemodialysis patients with type 2 diabetes mellitus. American Journal of Kidney Diseases, 54(5), 902-911.

Lippi, G., Favaloro, E. J., Montagnana, M., \& Franchini, M. (2010). C-reactive protein and venous thromboembolism: causal or casual association? Clinical Chemistry and Laboratory Medicine 48(12), 1693-1701.

Liu, Y., Coresh, J., Eustace, J. A., Longenecker, J. C., Jaar, B., Fink, N. E., et al. (2004). Association between cholesterol level and mortality in dialysis patients: role of inflammation and malnutrition. The Journal of the American Medical Association, 291(4), 451-459.

Lowrie, E. G., \& Lew, N. L. (1990). Death risk in hemodialysis patients: the predictive value of commonly measured variables and an evaluation of death rate differences between facilities. American Journal of Kidney Diseases, 15(5), 458-482.

Malgorzewicz, S., Aleksandrowicz-Wrona, E., Owczarzak, A., Debska-Slizien, A., Rutkowski, B., \& Lysiak-Szydlowska, W. (2010). Adipokines and nutritional status for patients on maintenance hemodialysis. Journal of Renal Nutrition, 20(5), 303-308.

Montazerifar, F., Hashemi, M., Karajibani, M., \& Dikshit, M. (2010). Hemodialysis alters lipid profiles, total antioxidant capacity, and vitamins $\mathrm{A}, \mathrm{E}$, and $\mathrm{C}$ concentrations in humans. Journal of Medicinal Food, 13(6), 1490-1493.

Moretti, H. D., Johnson, A. M., \& Keeling-Hathaway, T. J. (2009). Effects of protein supplementation in chronic hemodialysis and peritoneal dialysis patients. Journal of Renal Nutrition, 19(4), 298-303.

Movilli, E., Brunori, G., Camerini, C., Vizzardi, V., Gaggia, P., Cassamali, S., et al. (2006). The kind of vascular access influences the baseline inflammatory status and epoetin response in chronic hemodialysis patients. Blood Purification, 24(4), 387-393.

Nanayakkara, P. W., \& Gaillard, C. A. (2010). Vascular disease and chronic renal failure: new insights. [Review]. The Netherlands Journal of Medicine, 68(1), 5-14.

Nishizawa, Y., Shoji, T., Ishimura, E., Inaba, M., \& Morii, H. (2001). Paradox of risk factors for cardiovascular mortality in uremia: is a higher cholesterol level better for atherosclerosis in uremia? American Journal of Kidney Diseases, 38(4 Suppl 1), S4-7.

Pecoits-Filho, R., Barany, P., Lindholm, B., Heimburger, O., \& Stenvinkel, P. (2002). Interleukin-6 is an independent predictor of mortality in patients starting dialysis treatment. Nephrology Dialysis Transplantation, 17(9), 1684-1688.

Phillips, A., Shaper, A. G., \& Whincup, P. H. (1989). Association between serum albumin and mortality from cardiovascular disease, cancer, and other causes. The Lancet, 334(8677), 1434-1436. 
Sachdeva, M., Kovalchuk, O., Bitzer, M., \& Mokrzycki, M. H. (2009). Vascular access type and changes in inflammatory markers in incident dialysis patients: a pilot study. The Journal of Vascular Access, 10(3), 174-179.

Santos, N. S., Draibe, S. A., Kamimura, M. A., Canziani, M. E., Cendoroglo, M., Junior, A. G., et al. (2003). Is serum albumin a marker of nutritional status in hemodialysis patients without evidence of inflammation? Artificial Organs, 27(8), 681-686.

Sattar, N., \& Lowe, G. D. (2006). High sensitivity C-reactive protein and cardiovascular disease: an association built on unstable foundations? Annals of Clinical Biochemistry, 43(Pt 4), 252-256.

Sprague, A. H., \& Khalil, R. A. (2009). Inflammatory cytokines in vascular dysfunction and vascular disease. Biochemical Pharmacology, 78(6), 539-552.

Stenvinkel, P., Barany, P., Heimburger, O., Pecoits-Filho, R., \& Lindholm, B. (2002). Mortality, malnutrition, and atherosclerosis in ESRD: what is the role of interleukin-6? Kidney International Supplement(80), 103-108.

Stolic, R. (2010). Obesity in renal failure--health or disease? Medical Hypotheses, 75(6), 497500 .

Sun, H., Koike, T., Ichikawa, T., Hatakeyama, K., Shiomi, M., Zhang, B., et al. (2005). Creactive protein in atherosclerotic lesions: its origin and pathophysiological significance. American Journal of Pathology, 167(4), 1139-1148.

Taylor, L. M., Kalantar-Zadeh, K., Markewich, T., Colman, S., Benner, D., Sim, J. J., et al. (2011). Dietary egg whites for phosphorus control in maintenance haemodialysis patients: a pilot study. Journal of Renal Care, 37(1), 16-24.

Third Report of the National Cholesterol Education Program Expert Panel on Detection, Evaluation, and Treatment of High Blood Cholesterol in Adults (Adult Treatment Panel III) Final Report. (2002).

Trivedi, H., Xiang, Q., \& Klein, J. P. (2009). Risk factors for non-fatal myocardial infarction and cardiac death in incident dialysis patients. Nephrology, Dialysis, Transplantation: Official Publication of the European Dialysis and Transplant Association - European Renal Association, 24(1), 258-266.

Tsirpanlis, G., Boufidou, F., Zoga, M., Triantafyllis, G., Fatourou, A., Stamatelou, K., et al. (2009). Low cholesterol along with inflammation predicts morbidity and mortality in hemodialysis patients. Hemodialysis International, 13(2), 197-204.

Vaziri, N. D. (2009). Causes of dysregulation of lipid metabolism in chronic renal failure. Seminars in Dialysis, 22(6), 644-651.

Wystrychowski, G., Kitzler, T. M., Thijssen, S., Usvyat, L., Kotanko, P., \& Levin, N. W. (2009). Impact of switch of vascular access type on key clinical and laboratory parameters in chronic haemodialysis patients. Nephrology Dialysis Transplantation, 24(7), 2194-2200.

Xue, J. L., Dahl, D., Ebben, J. P., \& Collins, A. J. (2003). The association of initial hemodialysis access type with mortality outcomes in elderly Medicare ESRD patients. American Journal of Kidney Diseases, 42(5), 1013-1019.

Yeun, J. Y., Levine, R. A., Mantadilok, V., \& Kaysen, G. A. (2000). C-Reactive protein predicts all-cause and cardiovascular mortality in hemodialysis patients. American Journal of Kidney Diseases, 35(3), 469-476. 
Zimmermann, J., Herrlinger, S., Pruy, A., Metzger, T., \& Wanner, C. (1999). Inflammation enhances cardiovascular risk and mortality in hemodialysis patients. Kidney International, 55(2), 648-658. 


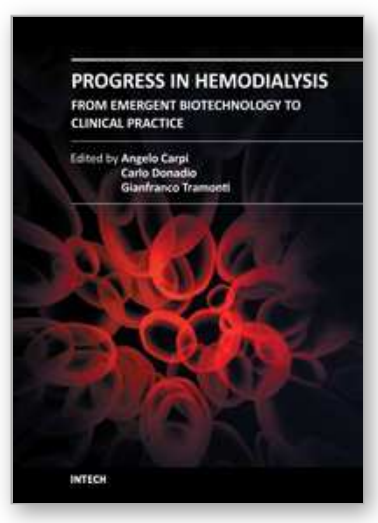

\section{Progress in Hemodialysis - From Emergent Biotechnology to Clinical Practice}

Edited by Prof. Angelo Carpi

ISBN 978-953-307-377-4

Hard cover, 444 pages

Publisher InTech

Published online 07, November, 2011

Published in print edition November, 2011

Hemodialysis (HD) represents the first successful long-term substitutive therapy with an artificial organ for severe failure of a vital organ. Because HD was started many decades ago, a book on HD may not appear to be up-to-date. Indeed, HD covers many basic and clinical aspects and this book reflects the rapid expansion of new and controversial aspects either in the biotechnological or in the clinical field. This book revises new technologies and therapeutic options to improve dialysis treatment of uremic patients. This book consists of three parts: modeling, methods and technique, prognosis and complications.

\section{How to reference}

In order to correctly reference this scholarly work, feel free to copy and paste the following:

Rodney G. Bowden, Neil A. Schwarz and Brian D. Shelmadine (2011). Malnutrition, Inflammation and Reverse Epidemiology in Hemodialysis Patients, Progress in Hemodialysis - From Emergent Biotechnology to Clinical Practice, Prof. Angelo Carpi (Ed.), ISBN: 978-953-307-377-4, InTech, Available from:

http://www.intechopen.com/books/progress-in-hemodialysis-from-emergent-biotechnology-to-clinicalpractice/malnutrition-inflammation-and-reverse-epidemiology-in-hemodialysis-patients

\section{INTECH}

open science | open minds

\section{InTech Europe}

University Campus STeP Ri

Slavka Krautzeka 83/A

51000 Rijeka, Croatia

Phone: +385 (51) 770447

Fax: +385 (51) 686166

www.intechopen.com

\section{InTech China}

Unit 405, Office Block, Hotel Equatorial Shanghai

No.65, Yan An Road (West), Shanghai, 200040, China

中国上海市延安西路65号上海国际贵都大饭店办公楼 405 单元

Phone: +86-21-62489820

Fax: $+86-21-62489821$ 
(C) 2011 The Author(s). Licensee IntechOpen. This is an open access article distributed under the terms of the Creative Commons Attribution 3.0 License, which permits unrestricted use, distribution, and reproduction in any medium, provided the original work is properly cited. 